\title{
Title: Exploring the 'active mechanisms' for engaging rural-dwelling older men with dementia in a community technological initiative
}

\section{Author's details:}

Dr Ben Hicks, Bournemouth University, Department of Psychology and Ageing and Dementia Research Centre, Poole House, Bournemouth, BH12 5BB. Email: bhicks@bournemouth.ac.uk

Professor Anthea Innes, Coles Medlock Professor and Director Salford Institute for Dementia, Salford Institute for Dementia, The Dementia Hub, Allerton Courtyard, Allerton Building, Frederick Road Campus, Salford M6 6PU

Dr Samuel Nyman, NIHR Career Development Fellow, Department of Psychology and Ageing \& Dementia Research Centre, Bournemouth University, Poole House, Bournemouth, BH12 5BB.

\section{Acknowledgements}

Many thanks to the men, their care partners and the volunteers who collaborated in this research. Thanks also to Dr Caroline Holland, Dr Tula Brannelly and Professor Mark McCormack for their insightful comments. 
Title: Exploring the 'active mechanisms' for engaging rural-dwelling older men with dementia in a community technological initiative

\section{Abstract:}

Research has suggested ecopsychosocial initiatives can promote a sense of well-being and inclusion in people with dementia. However, few studies have elucidated the 'active mechanisms' whereby such initiatives can achieve these outcomes, so hindering their generalisability. This is particularly pertinent when seeking to support community-dwelling older men with dementia who are reluctant to engage with traditional health and social care initiatives. This paper reports on a study that drew from the principles of Participatory Action Research to explore the 'active mechanisms' of a technological initiative for older men (65+ years) with dementia in rural England. An individuallytailored, male-only initiative, using off-the-shelf computer game technology (e.g. iPad, Nintendo Wii and Microsoft Kinect) was delivered over a nine week period. Multiple qualitative methods were employed including; focus groups, open interviews and extensive reflexive field-notes, to gather data from the perspective of twenty-two men, fifteen care partners and five community volunteers. The data were analysed thematically and interpreted using a masculinity lens. Three mechanisms contributed to the initiative's success: the use of the technology; the male-only environment; and the empowering approach adopted. The paper argues that initiatives aimed at community-dwelling older men with dementia would be advised to consider these gendered experiences and ensure participants can maximise their masculine capital when participating in them, by providing enabling activities, non-threatening environments and empowering approaches of delivery.

\section{Introduction:}

Globally, there are nearly 50 million people living with dementia and this is predicted to reach 131.5 million by 2050 (ADI, 2015). With no silver bullet cure on the horizon, researchers have called for a greater focus on 'care over cure' (Whitehouse, 2014). 'Ecopsychosocial' (Zeisel et al, 2016) initiatives 
are considered a core element of dementia care research (Kenigsberg et al, 2016; Orrell 2012) as they provide a cost effective means of supporting the well-being (Aguirre, Spector and Orrell, 2014; Dugmore, Orrell and Spector, 2015; Oyebode and Parveen, 2016) and psychological needs (Nyman and Szymczynska, 2016) of people living with the condition. The term 'ecopsychosocial' is used in this paper as it provides more positive language that defines the nature of the initiative, rather than its outcomes, and takes into account the contextual and environmental factors (eco) that are also likely to influence its success. Zeisel et al (2016) argue that this terminology enables academics and practitioners to better describe the full range of approaches and interventions within the dementia care field, thereby ensuring they can be more readily compared and connections can be drawn between them.

Despite the known beneficial outcomes of ecopsychosocial initiatives, there is a dearth of literature that provides a theoretical interpretation of the 'active mechanisms' (Dugmore, Orrell and Spector, 2015) that underpin them; that is the factors that work, appeal to, and support the positive outcomes for people with dementia. This means it is difficult to generalise the findings and consequently this hinders practitioners' abilities to effectively support people with dementia and ensure that resources are used most efficiently. As such, researchers have called for a better understanding of the factors for successful employment of ecopsychosocial initiatives (Dugmore, Orrell and Spector, 2015; Kenigsberg et al, 2016; Oyebode and Parveen, 2016). This is particularly important when working with older men (65+ years) more generally, and those living with dementia, who may find it difficult to address issues relating to their mental, physical and emotional well-being (White et al, 2011) and are often reluctant to engage with health initiatives; thereby increasing their risk of isolation, social exclusion and subsequently poorer health outcomes (Baker et al, 2014; Milligan et al, 2015; White, 2011; White et al, 2011). An acknowledgment of this issue has resulted in a call for men to be included within the global health equity agenda (Baker et al, 2014) and led to a specific focus on men's health policies in countries such as Australia (Australian Government, 2010), Ireland (Baker, 2015) and Brazil (Spindler, 2015). 
This suggests there is a need to develop a theoretically driven understanding of how to successfully engage older men with dementia in community ecopsychosocial initiatives. This paper addresses this by using an 'off-the-shelf' digital gaming technological initiative as a medium to explore the 'active mechanisms' for engaging community-dwelling older men with dementia living within three rural areas of England. In doing so, it provides recommendations for researchers, practitioners and policy makers when designing and implementing ecopsychosocial initiatives to support the well-being of this population. The research question central to this paper is: 'What are the 'active mechanisms' for engaging rural-dwelling older men (65 years+) with dementia in a community technological initiative?'

\section{- Masculinity as a theoretical lens}

The concept of masculinity provides a useful theoretical lens for addressing the above question. It sits within the wider context of 'gender,' which is a dynamic, social structure constructed by individuals, to perceive and make sense of the world around them (Connell and Pearse, 2015), and performed in particular social, cultural and historical contexts to establish themselves as 'male' or 'female' in the eyes of others (Courtenay, 2000). Masculinity ideologies (masculinities) refer to those cultural attitudes and beliefs that are thought to be 'male' (Connell and Pearse, 2015; Thompson and Bennett, 2015). They are developed and reinforced throughout a lifetime in accordance with the culture of the society for that particular time and place (Connell, 2005; Thompson and Bennett, 2016) and by adulthood, the majority of men will be aware of the standards and expectations that are associated with masculinity (Connell and Pearse, 2015; Connell and Messerschmidt, 2005).

The seminal work of Connell on 'Hegemonic masculinity' is integral for understanding work within this field. This masculinity is distinguished from other masculinities and embodies the current, 'most 
honoured way of being a man' (Connell and Messerschmidt, 2005; page 832) as defined by the historical era, social institution, or community. Whilst hegemonic masculinities may be practiced by only a minority of men it can act as a benchmark to guide men's gendered lives and judge their achievements (Connell and Messerschmidt, 2005; Thompson and Bennett, 2016; Thompson and Langendorefer, 2016; Twigg, 2018) as well as provide a hierarchical status that favours them over heterosexual women, people who identify as lesbian, gay, bisexual or transgender (LGBT), as well as other perceived 'lesser' masculinities (Connell, 2005; Connell and Messerschmidt, 2005).

These traditional Westernised masculinities that today's older men would have grown up in, expected them to follow conventional heteronormative masculinities and succeed in a career, and as husbands and fathers (Thompson and Langendorefer, 2016). It favoured men that were white, middle class, heterosexual, in their early midlife who displayed characteristics of stoicism, emotional impenetrability and fierce resolve, as well as strength, competitiveness and success, reliability, capability and a sense of control (Coston and Kimmel, 2013; Kimmel, 1996). To acquire these masculinities, men would suppress emotions, needs and 'feminine traits' (Kaufman, 1994). These masculinities would have been prevalent throughout the lives of today's older men and may have influenced their pattern of gender relations (Connell, 2005) and their health-seeking behaviours (Sloan, Conner, Gough, 2015); setting them up for difficult late-life experiences (Coston and Kimmel, 2013). Research also suggests they may be particularly pertinent in rural-dwelling men who can align more closely with hegemonic masculine ideals when compared to their urban male counterparts (Hammer, Vogel and Heimerdinger-Edwards, 2013; Levant and Habben, 2003).

Despite some discourses depicting a de-gendering process in later life (Sandberg, 2018), as men age, research has suggested they continue to draw from a gendered lens when understanding their experiences and constructing their identities (Hurd Clarke and Lefkowich, 2018; Twigg, 2018). For some older men, their constructed ageing masculinities can be closely aligned with this hegemonic ideal and so result in them downplaying health concerns (Hurd Clarke and Bennett, 2013), avoiding 
seeking help (Yousaf, Grunfeld and Hunter, 2015) and positioning themselves relationally superior to heterosexual women and LGBT populations (Hurd Clarke and Lefkowich, 2018). They may also adopt masculine norms that are reminiscent of their younger hegemonic masculinities. For instance, Thompson and Langendorefer's (2016) found that as no 'blue print' for ageing exists, some older men still sought to follow, yet struggled to obtain, these traditional masculinities. These masculinities may result in the social exclusion and subsequent health deterioration of older men due in part, to their resistance to participate in community-based social groups as well as community-based health services and preventative health activities (Milligan et al, 2015; White, 2011; White et al, 2011). However, other studies have found that as some men age, and in response to life changes, they reinterpret their masculinities. This includes willingly embracing the opportunity to abandon the hyper masculine work culture in favour of developing other aspects of their identities (Slevin and Linneman, 2010) or to focus on their family life (Wentzell, 2013), as well as openly acknowledging their vulnerability (Hurd Clarke and Lefkowich, 2018) and consequently engaging in help-seeking behaviours (Courtenay, 2000).

Despite contrasting findings, these strands of research suggest that, whilst there is a tendency for research to construe older men as androgynous and stripped of their gendered, sexual identity (Milligan et al, 2015), gender and masculinities still remain an important determinant for men's experiences and health behaviour in later life. As such, it is necessary to adopt a more refined understanding of how to engage the growing population of older men more widely (Milligan et al, 2015) as well as those living with dementia.

\section{- Masculinity and dementia}

Gender is rarely acknowledged when exploring the lived experiential accounts of people with dementia (Bartlett et al, 2016; Hulko, 2009; Phinney, Dahlke and Purves, 2013). In part, this may be attributed to some dehumanising discourses that can engulf dementia and result in the degendering of people living with the condition (Sandberg, 2018). Despite this, the limited research 
suggests masculinities are an important influence on the lives of men. Hulko (2009) demonstrated that dementia was perceived as more devastating to those socioeconomically privileged participants such as white, middle to upper class men, and they required the involvement of others to alleviate issues. This was opposed to less privileged individuals who perceived dementia as 'no big deal' in the grander scheme of challenges they contended with in their daily lives. Furthermore, Phinney, Dahlke and Purves (2013) highlighted that as two Canadian community-dwelling older men with dementia became less active and less independently capable, they expressed a sense of loss to their masculinity and this resulted in periods of frustration. Consequently, in an attempt to regain or sustain their masculinities, they often opted to undertake work-related pursuits and masculine activities that had filled their lives in the past. They were supported in these endeavours by their care partners and families who noted the importance of providing the men a sense of continuity so they felt connected and included. The families also discussed their desire to uphold the men's role as head of the family despite the challenges and tensions that this could result in.

Therefore, similar to older men more generally, this limited literature highlights the importance of masculinities in the experiences of community-dwelling older men with dementia. Consequently, it is important to consider them when engaging this population. However as Bartlett et al (2016) posits, it is still unclear how health and social care professionals can incorporate gender awareness into their work. This study provides recommendations on how this may be achieved.

\section{- Engaging community-dwelling older men in ecopsychosocial initiatives}

The 'Men in Sheds' literature has been successful in elucidating factors for engaging communitydwelling older men, particularly those in rural areas, and demonstrating benefits for 'members' mental, physical, social and emotional health and well-being (Cordier and Wilson, 2014; Waling and Fildes, 2017; Wilson and Cordier, 2013; Wilson et al, 2015). The 'sheds' are often located in community spaces or residential care settings and are equipped with a range of workshop tools. Milligan et al (2015) suggest part of their appeal is their ability to provide a gendered space that 
enables older men to perform and reaffirm their masculinities. This includes undertaking activities they have been accustomed to throughout their lives, in an informal, less pressurised setting as well as socially interacting within a male-only environment. This former point resonates with other research that has demonstrated older men (Genoe and Singleton, 2006; Wiersma and Chesser, 2011), and those with dementia (Phinney, Dahlke and Purves, 2013), enjoy engaging in activities that are reminiscent of their younger masculinities; particularly when they are not required to compete as they may have done in their youth. However, Wiersma and Chesser (2011) warn that these leisure activities, if performed unsuccessfully, can reinforce the stigma attached to the social construction of an 'old man' and so detrimentally impact on men's well-being.

Whilst this research offers a more refined understanding of engaging community-dwelling older men, Milligan et al (2015) note that participants with dementia struggled to socially connect. As posited by other research (McParland, Kelly and Innes, 2017) this was partly attributed to the reluctance of those without cognitive impairments (through discomfort or anxiety) to socialise with members with dementia. This highlights the need for further research to outline the factors required to promote an inclusive and non-threatening, or 'conceptually safe' (Wiersma et al, 2016; Phinney et al, 2016) community ecopsychosocial initiative that appeals to older men with dementia.

A limited number of studies have addressed this aim, and all have used the medium of football (Carone, Tischler and Dening, 2016; Solari and Solomons, 2012; Tolson and Schofield, 2012). This research has highlighted certain factors for success including, repositioning the men as experts during the conversations (Tolson and Schofield, 2012) and providing a male-only environment that encourages a 'dementia-free' (no talk about dementia) zone (Carone, Tischler and Dening, 2016). However, these studies offer no discussion linking their findings to theories of masculinities. Therefore, further research that adopts a masculinity lens is likely to provide theoretical insight into the 'active mechanisms' for engaging community-dwelling older men with dementia; thereby enhancing the generalisability of the work and better informing dementia practitioners. 


\section{- Using off-the-shelf digital gaming technology}

Over recent years, the role of technology to support people throughout their 'journey with dementia' has become better acknowledged (Kenigsberg et al, 2017; Lorenz et al, 2017; Meiland et al, 2017). These various forms can include Assistive Technology (AT) such as medication aids or locator devices, Information and Communication Technology (ICT) including telecare and telemedicine, as well as off-the-shelf, digital gaming technology. Scholars have argued that technology development within the dementia field has primarily focussed on providing safety and security for people living with the condition and their care partners. Consequently there is a need to better understand how it can be used to provide people with opportunities for new experiences and to engage in leisure activities that are stimulating, enjoyable and fun (Astell, 2013; Joddrell and Astell, 2016); equally important facets for living well with dementia. This is particularly pertinent in rural areas (Baker et al, 2017) including the UK (Townsend et al, 2013), where the rural/urban digital divide continues; although as Bowes et al (2018) note this is starting to change across rural Europe with dementia-specific and off-the-shelf technologies (such as iPads) becoming more widespread within dementia care practice.

Research within this field has been slowly growing and therefore contributed to the decision to select off-the-shelf digital gaming technology, given the potential benefits it may offer both dementia practitioners and people living with the condition. For instance, this technology is ubiquitous within society, ensuring it is more readily available for purchase and use than other forms of dementia-specific technology, and furthermore it may not be associated with the same stigma that can accompany these other devices (Meiland et al, 2017). Emerging research has also demonstrated the benefits that this technology can have for the quality of life and social inclusion of people with dementia. A synthesis of the literature (Cutler 2018; Dove and Astell, 2017; Cutler, Hicks and Innes, 2016; Joddrell and Astell, 2016) suggests this includes providing an opportunity for people to; interact with novel devices to remain connected to contemporary society; continue their life-long 
learning; challenge themselves and master new and sometimes complex skills; (re)engage with meaningful and enjoyable activities that promote cognitive stimulation, mild physical exercise and social interaction; increase self-confidence by challenging their perceptions of their own capabilities; and challenge public views regarding the competencies of people living with dementia. Finally, research has also pointed to the gendered nature of technology (Ravneberg, 2012), with these gaming 'gadgets' of modern society potentially appealing more to men rather than women.

All of these factors suggest that engaging with off-the-shelf gaming technology is likely to be a new experience for rural-dwelling older men with dementia, but one that has the potential to provide an appealing activity that is beneficial for their well-being.

\section{Research approach}

This study sought to address the issue of social exclusion for rural-dwelling older men with dementia within an English county. The research was initially framed as a Participatory Action Research (PAR) study, although, as outlined below, it did not adhere strictly to the PAR processes but rather drew from the principles of the approach (Chevalier and Buckles, 2013; Reason and Bradbury, 2008; Schneider, 2012). These centred on the participation of the men throughout the research and included; promoting their voices at all opportunities, situating them as 'experts' and providing a platform for mutual learning, as well as upholding their rights for autonomy and respect. This approach is widely advocated for enabling the inclusion of people with dementia throughout the entire research process (Dupuis et al, 2012, 2016a; Wiersma et al, 2016) and ensured the initiative was fit-for-purpose.

As part of the PAR process the men were asked to name their group, feedback on the delivery of each session (including the set-up of the room and the technology and games used) as well as the final analysis, and take photographs (this was carried out by one man in each group who showed a 
desire to take on this role) and provide quotes to illustrate their experiences of participating in the study. These latter aspects were used as evidence to support three successful funding bids (one per group) to a local organisation, which enabled the initiatives to continue beyond the research period and provided an indication that the approach was welcomed amongst the county.

Ethical approval for the study was received from the lead author's institution ethics board.

\section{- The rural settings}

Working in collaboration with dementia support charities based within the county, the research team identified the rural areas that would receive the technology initiative. This decision was made to ameliorate time and resource restrictions placed on the study.

The 2011 Rural-Urban Classification (DEFRA, 2015) was used as a guide to define the rural settlements and three rural areas were selected to host the initiative. Adopting a multi-site design enabled the findings to be compared across the different rural locations, thus improving the generalisability of the research. Table 1 presents a demographic overview of the rural locations with data gathered from the 2011 Census.

Location One could be considered a 'bypassed' rural community (Keating et al, 2013). It had poor services and transport links, and was suffering from economic depression, with most of the local funding being directed towards an urban conurbation, which was situated nearby. Consequently, the technology initiative was one of very few services being offered locally for people with dementia (and the only one specifically for men with dementia). Conversely, Location Two and Location Three were more consistent with 'bucolic' rural communities (ibid) with good resources and assets that were attracting recent retirees and London Second-Home owners (this was ascertained during informal discussions with local residents during the recruitment phase of the study). Location Two had good transport links to a nearby major urban conurbation whereas Location Three was surrounded by rural hamlets and isolated dwellings. Both of these rural locations provided some 
formal activities for people with dementia, although none offered technological initiatives or groups specifically for men with dementia.

\section{- The Technological Initiative}

Developing the Technological Initiative (TI):

The technology used during the $\mathrm{TI}$ was selected based on an extensive review of the literature, which outlined the range of off-the-shelf platforms that had been previously explored with people with dementia, and the findings from four consultation sessions held in the county with older men with dementia, their care partners and local dementia practitioners. The details of the consultation sessions are reported elsewhere (Hicks, 2016), although their implications for the design of the main TI are summarised below.

1. Technology used within the TI: The men were offered an opportunity to use an iPad, Nintendo Wii, Nintendo DS, Nintendo Balance Board and Microsoft Kinect. Findings from the consultation sessions suggested the men struggled to engage with the Nintendo DS due to the small screen size. Consequently it was removed from the main TI as many of the activities could also be undertaken on the iPad (something the men found easier to interact with). Furthermore, although some men found it difficult to interact with the Nintendo Wii within the short timeframe of the consultation (due to the combination of hand movements and simultaneous button pressing), this remained within the $\mathrm{TI}$, as previous research has suggested people with dementia can engage with this motion sensor technology provided they are given appropriate time to do so (Cutler, 2018; Dove and Astell, 2016; Fenney and Lee, 2010; Leahey and Singleton, 2011). However as a result of this, it was decided to introduce the Microsoft Kinect within the preliminary sessions, as the men found this easier to engage with as there was no need for a controller. Once the men were accustomed with 
the sensor technology the more complicated games and movements required on the Nintendo Wii were introduced.

2. Recruitment for the TI: Following feedback from the men that the word 'technology' could evoke fear or a misunderstanding of the TI (ie. it was for educating them on using computer packages such as Microsoft Word or emails) this was removed from the recruitment flyers and terms 'gadgets' and 'gismos' used instead, as recommended by the participants. The groups were also promoted as 'social clubs' to further remove the focus from the technology and to highlight the other potential benefits of the TI as outlined by the men, such as having the opportunity to try something new and to socially interact with others.

3. Set-up of the TI: Although care partners were present during the consultation and provided reassurance to the men, it was noticeable that the men appreciated the opportunity to engage in the activities on their own. Consequently, during the $\mathrm{TI}$, care partners were invited to stay and watch the activities from afar but not actively participate in the groups.

Interestingly, only care partners in Location Two remained to watch the TI, where they sat away from the activities and reported that they used the time as an informal support group. This ensured that the male-only environment could be maintained throughout the $\mathrm{Tl}$; that is an environment where only the men were actively participating in the activities, group discussions and development of the initiative. Furthermore, although some of the men were initially reluctant to engage with the games, by watching others it encouraged them to also participate. This is consistent with Kahlbaugh et al (2011) who suggest co-viewing is an important unifying process that can create a more relaxed social environment. As such, it was seen as important that the TI placed an emphasis on group activities as this would help to ameliorate any fears men had around using the technology and promote a more socially engaging atmosphere.

\section{Delivering the TI:}


The $\mathrm{TI}$ consisted of three individual deliveries of a programme that ran in three rural locations of the county. Each programme continued for a total of nine weeks with one session per week lasting for two hours including breaks for refreshments and informal discussions.

The TI was individually tailored towards the interests and capabilities of the men in each group as advocated by a person-centred approach (Cohen-Mansfield, 2010; Kolanowski et al, 2011). This meant that often the activities varied across the three rural locations, although there were three sessions that remained consistent (1,2 and 9). These were:

1. Introductory session (1) with two main activities that aimed to promote light hearted dialogue between the men. The first was an 'ice-breaker' activity using the camera application on the iPad. The men were asked to take a photograph of another person around the table and once their picture had been taken they were invited to introduce themselves to the group. This activity engaged the men with the technology and provided valuable information that could be used to tailor subsequent activities towards their interests. The second activity involved the men naming their group. This encouraged them to take ownership of it and removed any associations with it being a support group for men with dementia. This name was used throughout the remainder of the research (Location One- Old Boys, Location Two- Done Roaming and Location Three- Marching On). Within this session, the sensor technology (Microsoft Kinect) was also introduced through playing the Kinect Sports Golf game, which was slow moving and required simple, basic movements to interact with it. This was important as research has highlighted detrimental impacts on people with dementia's willingness to re-engage with technology if they fail at their first attempt (Hicks and Miller, 2012).

2. Session 2 introduced the 'Game of Life' application; a board game that works in conjunction with the iPad (which was connected to a TV screen). This game was used as an additional medium to introduce the iPad (beyond the camera application) to the men and also 
encourage discussions about their lives. Again this information was used to tailor future sessions and highlight any similar life histories or interests between the men.

3. Final session (9) was used to undertake an extensive discussion with the men about their experiences of taking part in the Technological Initiative (discussed in the research methods).

During the remaining sessions, other technologies were introduced to the men at different points such as the Nintendo Wii and the Nintendo Balance Board, and they were encouraged to suggest the games they wished to play. The majority of the activities were played within a group setting, although on occasions some of the men elected to use the iPad for board/music games on their own or in pairs, often whilst they waited for others to arrive to the session. The iPad was frequently connected to a large television to enhance its inclusivity, and the primary aim of these activities was to promote discussions between the men about their lives and interests. This included finding songs they enjoyed on YouTube or photographs of objects and places that were meaningful to them as well as using Google Earth to virtually visit the places they previously lived or had stayed on holiday. The motion sensor technology was used to promote physical activities that the men enjoyed such as golf, tennis and bowling. They were encouraged to play on their own (or in pairs) and compete against others in the group, or work together to challenge a computer opponent (eg. play a hole each in a 9 round golf game against the computer). The majority of the games were embraced by the men and enjoyed to a more or lesser extent; however a few were rejected after limited play by the different groups. These included the fishing (considered slow moving, boring and difficult to control the rod) and Beatles Rock Band (fast moving and difficult to time the appropriate actions) by the Old Boys, as well as the Wii Boxing (unrealistic) and Mario Kart (fast moving and difficult to navigate the racer) by the Marching On group. Table 2 provides a full breakdown of the games that were introduced throughout the Technological Initiative. 
During any activities or discussions, no reference was made to the men's dementia unless it was initiated by the men themselves. The activities focussed solely on promoting the men's capabilities and engaging them in discussions about the wider context of their lives over and above their diagnosis of dementia. This is consistent with other initiatives that have sought to appeal to men with dementia through the creation of 'dementia-free' zones (Carone, Tischler and Dening, 2016).

\section{- $\quad$ The rural venues}

Each rural venue was spacious enough to safely run the activities, had Wi-Fi availability as well as kitchen facilities to provide refreshments. They were also situated within a central location to enhance their accessibility. The venues were set up to support both the group activities and the oneto-one discussions. This included having a large open area, with chairs set up in a semi-circle around the television for the activities on the motion sensor devices or a quiet area with tables, chairs and refreshments that would facilitate conversations or provide a place the men could retreat to if they desired. A separate area was provided at the back of the venue for any care partners wishing to stay and watch the activities; although this only occurred in the Marching On group.

\section{- Role of the researcher during the delivery of the TI}

The lead author acted as facilitator and primary researcher of the Technological Initiative, with the aims of introducing the men to the various technologies and games, supporting them to successfully engage with them, and collecting their feedback throughout each session to inform the subsequent sessions. During the $\mathrm{TI}$, in an attempt to democratise the research process and breakdown the barriers between researcher/facilitator and participant, the lead researcher also engaged with the activities; sharing aspects of his life during discussions and pairing with the men during the competitive gaming activities. Through these means it was hoped that he could transition from a position of group 'outsider' to 'insider' (Bryce, 2012) through the research process; thereby enabling him to develop a trusting relationship with the men that could result in richer and more honest data 
being collected. This process may be particularly important in rural communities where 'outsider' professionals can be treated with initial distrust and scepticism (Szymczynska et al, 2011).

\section{- Participant recruitment}

A purposive sample of 22 older men living in rural communities (65 years+) with a dementia diagnosis and five community volunteers participated in the TI. In addition to this, 15 care partners of the participating men took part in interviews that sought to elicit greater insight into their daily rural lives (as a means to contextualise the $\mathrm{TI}$ ) and the perceived impact of the initiative (particularly immediately after the sessions and in the subsequent days). All participants were recruited through Memory Support Workers and Activity Leads within the communities as well as recruitment flyers that were distributed in local buildings (churches, pubs, libraries, halls) and in newspapers. The Process Consent procedure (Dewing, 2008) was followed to ensure the men's on-going consent throughout the research. A demographic overview of the participants is shown in Table 3.

\section{- Research methods}

Qualitative methods, advocated for exploratory research (Flick, 2014; Robson, 2011) and eliciting 'active mechanisms' (Dugmore, Orrell and Spector, 2015), were employed throughout the research. Multiple methods, including researcher's reflective field notes, aimed to collect data from the men as well as the care partners and volunteers as a form of 'triangulation' to add further insight into the research topic (Flick, 2014). All of the sessions were filmed and then reviewed by the lead researcher when making reflective field notes. During the $\mathrm{TI}$, informal discussions were undertaken with the men as they engaged with the technology or more formally at the end of each session during a longer focussed conversation. These discussions asked them to reflect on the technology and games used as well as the structure and format of the sessions. The data collected were used to inform the subsequent sessions of the TI. This data was supplemented with information obtained from the men during a formal focus group at the end of the nine week initiative (as part of the $\mathrm{TI}$ ) as well as a oneto-one, face-to-face open interview held at the men's home after the final TI session. These multiple 
qualitative methods were employed to offer the men varied opportunities to feedback on the TI, in both a social setting, where they could share ideas amongst themselves (during the focus groups) and an intimate setting, where they could discuss their views in more detail and divulge information they might not have felt comfortable sharing within a group context. Table 4 provides an overview of the men that took part in each method, as well as the care partners that were interviewed.

\section{- Data analysis}

All data were transcribed, anonymised and uploaded on to Nvivo 10 to manage the analysis process. An inductive 6-phase thematic approach, as outlined by Braun and Clarke (2006), ensured the themes were grounded in the original words of the participants. The data obtained from the men were initially analysed and following this, volunteer, care partner and reflective field-note data were examined to elicit further insights. During construction of the themes, detailed discussions were undertaken between the research team to provide rigour to the analytical process. Once the themes were constructed, a cross case analysis was undertaken to explore any differences between the groups.

The final themes were presented to the men during a feedback session within their group around five months after the initiative finished. No changes were made to the themes or their subcomponents post-discussions.

\section{Findings}

The data demonstrated the TI provided the men with beneficial outcomes for their well-being and sense of social inclusion. These findings are not the focus of this paper and can be found elsewhere (Hicks, 2016). This paper examines the factors that appealed to and engaged the men in the TI. Three themes, constructed from the data, highlighted the mechanisms that were crucial for its success. These were the enabling technological activity, the conceptually safe male-only 
environment and the empowering approach. These, along with their subthemes, are discussed in more detail below.

\section{An Enabling Technological Activity}

The technology was important to the TI's success through providing a jovial activity that was meaningful to the men, enabled them to express themselves and re-connect with a modern society.

\section{- Meaningful, accessible and jovial activity}

The TI provided an enjoyable 'outlet for everybody' (Phil, Done Roaming, Focus Group) or 'escape from home lives' (Dick, Marching On, Interview) that the majority of men welcomed within their rural location.

'Yeah getting out of the house and getting away from your siblings or your wife or whatever is going on at home (is a benefit).' (David, Old Boys, Focus group)

The men, their care partners and the volunteers discussed the importance of providing a range of technologies and games that enabled the activities to be tailored towards the men's previous interests, thereby enhancing the Tl's appeal and enjoyment, and ensuring it 'did not become stale' (Gordon, Marching On, Focus group).

'I think a lot of it is very good...and you find, good lord, what a funny game this is. And, it's great fun, and you can see it, and all of them respond (the men), I respond, I don't always win but it's great!'(Simon, Marching On, Interview)

The sensor technology supported sporting or active games such as boxing, tennis, golf or bowling (all embraced by the majority of men) and the iPad was attractive to men with previous interests in board games such as chess (Bill) or backgammon (Joe). Furthermore, the intuitive nature of the games ensured the men who had previously played games such as golf in reality, would automatically adopt the appropriate actions/stance with little prompting. This enabled them to 
engage with the game with minimal support, and so re-connect with activities that were once important to them.

'I loved the golf game...I can't go out and play on a course anymore. I don't have the money or equipment and... I'm not physically able to now but I love it...and I played it and I hit a good shot occasionally. About once every three weeks!' (Tel, Marching On, Interview) 'Yes he really enjoys it. He used to play golf and fly fishing. He misses his golf and was in his element the other day when you played. I was driving him back and he just said: "I feel so elevated." And I said: "You mean like happy?" And he said: "Yeah. We played golf today and I haven't played in ages!"' (Maggie, Done Roaming, RFN session seven)

Indeed, on some occasions when the activities could not be tailored towards the men's interests or perceived capabilities, they declined to participate. In two extreme cases, care partners from the Marching On group believed their husbands, Chris and Harry, left the TI as the activities did not align with their previous interests. However, it should be noted they never watched the $\mathrm{Tl}$, and so could only speculate. Unfortunately, when interviewed both men were unable to remember the $\mathrm{Tl}$ in great detail.

Furthermore, the games' light hearted music, colourful graphics and jovial content along with the actions required to engage with the sensor technology (such as hitting moles around the head with a mallet or hula hooping) ensured the activities were humorous. The men and the volunteers noted that this was appealing as it ensured the men experienced little pressure when engaging with the activities.

'Those games I will tell you are a cracker!...there's so much harmonies and laughs and jokes and you know, and it's good.' (Bill, Old Boys, Interview)

'Those games were really good and the golf one we had a lot of fun with...Yeah that bloody golf game, we had a lot of fun that day. It's a great method of getting a laugh as well as 
encouraging them (the men) to be interested in, and part of, a group.' (Greg, Done Roaming, Volunteer, Interview)

Indeed, on the rare occasions the men felt a sense of pressure to perform, the games lost their appeal. These instances usually occurred when the games were linked to activities the men were once competent with in their younger years, and as such they perceived a requirement to perform to a certain standard. For example, some men in the Marching On group who had previously been boxing coaches, struggled to engage with the boxing game on the Nintendo Wii. As they failed to hit their opponent, they became increasingly frustrated with their performance as well as the volunteer supporting them, with one man shouting: 'what would you know? How many fights have you been in?' (Peter, Marching On, RFN session three). During feedback, Tel suggested he hadn't liked the game as it was 'too unrealistic' (Tel, Marching On, RFN, session three) and consequently the game was never played again. This was also the case in session 3 with the Old Boys, when David struggled to engage with tennis (a previous interest of his) on the Nintendo Wii, and yelled at his female avatar 'you're worse than my wife' (David, Old Boys, RFN Session 3). After a few unsuccessful attempts he gave up on the game and refused to play it again. Although instances where the games had a detrimental impact on the men's well-being were rare, they needed to be carefully managed. This was usually overcome by placing the 'fault' on the mechanics of the technology rather than the individual; thereby alleviating some of the threat that the men felt to their sense of identity and their perceived capabilities.

This finding demonstrates the importance of tailoring activities to the interests and capabilities of older men with dementia and ensuring they are not placed under any pressure to perform to certain standards.

\section{- An opportunity to express themselves}

The activities enabled the men to express themselves both physically and verbally, and so garner respect from others present. Physical characteristics including athleticism and strength were 
demonstrated by the men when engaging with sensor technology games such as boxing and tennis. In particular, this technology enabled the men to display competitive characteristics during activities such as bowling and golf. As Angela noted:

'Well it made him do a little bit of exercise, but it also boosted his morale, in as much as he felt he was achieving, he felt that he was you know winning the game' (Angela, Marching On, Interview)

Interestingly this competitive element was most pronounced in the Done Roaming group where care partners watched from a distance and would support the men from afar by shouting words of encouragement and heaping praise on them if they were successful. This appeared to enhance the men's enjoyment of the activities and their sense of achievement as they sought to be crowned 'champion of the group' (Barry, Done Roaming, RFN session six).

'The competition was good...it was a healthy one and everybody...they could feel the progress they were making inside themselves.' (Phil, Done Roaming, Interview) Furthermore, the technology provided a 'scaffold' (Upton et al, 2011) or prompt for social interaction and communication; whereby the men could position themselves as experts and highlight aspects of their lives and their achievements. Whilst there were instances of this occurring during games on the sensor technology, it was most prevalent when using applications on the iPad, as this provided instant access (through an internet connection) to applications, music, videos and pictures that could encourage and sustain social interaction and so were 'really good for getting the men to talk about their lives' (Graham, Old Boys, interview).

'Terry used the iPad to locate areas of East London where he grew up. We had an interesting chat about this and he was able to find his old street using Street View...He discussed the places where he had worked and showed me the streets he had frequented. He repeatedly 
commented that it had all changed with all the houses that had sprung up everywhere.' (Done Roaming, RFN session 4)

This finding demonstrates the importance of providing activities that enable older men with dementia to confidently and independently express themselves both physically and verbally, and so garner respect from others present.

\section{- 'Clobber along with the rest' and re-connect with modern society}

The data highlighted that whilst the majority of the men were initially unfamiliar with the technology, they welcomed the opportunity to engage with it. The men perceived the technology as a facet of modern society and so appreciated the chance to develop skills and knowledge that enabled them 'to clobber along with the rest of them' (Jess, Marching On, Focus group).

'But seriously it's progress. Everybody wants to be involved in progress don't you? No matter what you do. It opens a new chapter in your mind doesn't it? You would think it would never work but it does...But what you've proved is that things like that machine have opened our education.' (Phil, Done Roaming, Focus group)

For some men such as Joe, David (Old Boys) and Jess, engaging with the TI spurred their interest in buying the technology for their home so they could continue to play the games with their wives or grandchildren. As David noted:

'It (the TI) sets you up to use it (technology) at home as well doesn't it? So that you don't just use it there but when you come home you can look back on what you did and then continue where you left off.' (David, Old Boys, Interview)

Whilst mastering these technological skills was integral for the men's sense of achievement it also encouraged them to challenge negative assumptions around their capabilities, including their own perceptions of their abilities as well as those of the volunteers and the care partners. This was important for enhancing their sense of positive well-being. 
'As far as I'm concerned, I come here very glum, fed up and sorry for myself and I go away thinking that I can still do something even if it's something silly. I can still do something.' (Doug, Done Roaming, Focus group)

'Just interesting to see how people who initially didn't look like they were that involved in it...even capable of being involved with it ... took to it...So just to see that obviously it makes me look at things differently...and I don't now automatically assume that they are (unable to participate), you know, probably give them more time than maybe I would have before.' (Tom, Old Boys, Volunteer, Interview)

This demonstrates the importance of enabling older men with dementia to engage in new and modern activities and to continue their learning so as to ensure they feel a connection to contemporary society.

\section{A Conceptually 'Safe' Male-Only Environment}

The data suggested that the male-only environment was a 'stroke of genius' (Caroline, Old Boys, Care Partner, interview) and favoured by the men. It provided them with a non-threatening space where they felt comfortable speaking openly and did not have to temper their masculinities; thereby enabling them to develop a sense of comradeship and solidarity with others present.

\section{- A comfortable and familiar environment for self-expression}

The data suggested the male-only environment encouraged the men to relax and engage freely in conversations with one another. This chance for socialisation was particularly important for some men, who suggested they were rarely afforded this opportunity in their daily lives.

'Well it (the TI) helped to sort of meet other people. I don't socialise that much.' (Bill, Old Boys, Interview) 
The men reported that their discussions would have been more restricted if women were present, as they would have 'disapproved of the swearing' (Joe, Old Boys, Focus Group) and the topics of conversation or would 'take over' (Joe, Old Boys, Focus group) so that it became a 'woman's club' (Bill, Old Boys, Interview). Consequently, they perceived this would have inhibited their ability to express themselves freely.

'If you can swear, which now and then you can do, then you would feel offended with the women there. Then they would take over. And you would never get a word in edgeways and the woman always has the last word. I feel more relaxed with just men only.' (Joe, Old Boys, Focus group)

'It's good amongst the boys you know? (With women)...you would sort of be limited in a lot of ways...you would have to be reasonable and so forth!' (Dick, Marching On, Focus group) 'Yeah I think it's good (having a male-only environment)...All these blokes if they got annoyed would swear and relieve their feelings if they needed to do that...and they can here.' (Doug, Done Roaming, Focus group)

These sentiments were also conveyed by care partners and volunteers who stated that the environment enabled the men to engage in 'male banter' (Tom, Old Boys, Volunteer, Interview) and conversations that were 'a bit naughty' (Jean, Done Roaming, Care Partner, Interview), as well as provided them sanctuary from a world that could potentially feel 'over womaned' (Veronica, Marching On, Interview).

'Well, I think it's a good idea (men-only), I think too many of these Coffee Mornings and things that we go to are full of women. There seem to be more women than men, and I think the men only thing is good.' (Sue, Marching On, Interview) 
Furthermore, care partners reported that this environment was one that the men would have been accustomed to during their younger years and working life, and so this sense of familiarity would have contributed to the men's feelings of security and so enhanced the appeal of the TI.

'...all his working life he's been used to the company of men, he's never worked with women. And, all his hobbies were always to do with other men...the normality of socialising has, historically in his life, been with men and this is what he feels comfortable with.' (Caroline, Old Boys, Care Partner, Interview)

This male-only environment was rarely afforded the men in their current daily lives, but was viewed by both them and their care partners as important for enabling self-expression.

\section{- An opportunity for comradeship and solidarity}

As the men were able to express themselves freely, they developed a sense of 'comradeship' (Doug, Done Roaming, Focus group) and togetherness. They spoke in affectionate terms about one another, noting the 'warm side to the group' (Dick, Marching On, Interview) and the 'similar attitudes' (Ken, Old Boys, Focus group) where people 'were only too glad to add their little bit' (Dick, Marching On, Interview).

'I go there and it's like alright Bob how are you doing? I don't think there's any there that will say anything against me. Yes they're good lads (laugh).' (Bob, Old Boys, Interview)

Furthermore, although the men's dementia was never openly discussed, the data suggested the environment enabled the men to connect emotionally around this issue, acknowledging all members were all on a 'similar level' (Dick, Marching On, Focus group) but 'you're not on your own' (Gordon, Marching On, Interview). This was appealing to the men and helped to provide them with comfort and reassurance, and there was a sense that if women were present then these connections would have been hindered as 'blokes take notice of others because they are blokes' (Doug, Done Roaming, Focus group). 
'Well it's good to be with people and talk about things you have that you've experienced, and of course, meeting the Herberts in the same problem as yourself, it's a bit reassuring really.' (Jess, Marching On, Interview)

'...you don't walk about with a placard saying I've got dementia...So it's helped me by seeing other people had the same problem as I had. Whether it was to the same degree or worse, you know, but there was other people there that I could see had got the same problem, and they were living their life okay.' (Joe, Old Boys, Interview)

However, it is noteworthy that through enabling the men to freely express themselves then the 'diversity' of the group and the 'certain attitudes or interests' became prominent, thereby making it difficult for certain men to 'gel' (Tel, Marching On, Interview). For instance in the Done Roaming group the tensions often centred on Doug, who felt his recent diagnosis of dementia was a threat to his masculinity. As such he sought to 'other' the rest of the men in the group, refusing to sit with them at the beginning of the early sessions of the initiative and instead watch from a quiet corner of the venue where he could talk to the volunteer. This was manged within the group by slowly encouraging him to engage in activities with the men and join in discussions that centred on their lives, rather than dementia. Consequently it was noticeable that, overtime he formed a bond with them and used the group as a source of support, although he was keen to disassociate himself with them during his final interview.

'Well, I found them a bit odd actually (other men in the group), but then I'm a Londoner. So I did find it very hard to become a friend of...an associate. Alright, they're there and they're in the same poo as you are, so that's about all it amounts to. I wouldn't want to visit them or go out with them. I don't know.' (Doug, Location Two, Interview)

Unfortunately within the Marching On group the men's conflicting interests were more difficult to manage and resulted in a few men making disparaging comments to others or refusing to engage 
with them. For instance, Tel would roll his eyes when Chris spoke of his love for classical music and vice versa when Tel would speak of his days as a boxing coach. At one point after Chris played a classical piece of music on the piano, Dave exclaimed 'yeah I like music, but none of that rubbish' (Dave, Marching On, RFN Session 2). Others such as Jess also commented 'oh ladeda, very posh!' (Jess, Marching On, RFN Session 1) when Harry spoke at length about his home in the country and the tennis courts and horses he owned. This made for noticeable and uneasy tensions in the group that were only truly resolved when these men (Tel, Dave, Chris and Harry) left. As Josh the Marching On volunteer spoke of during his interview:

'Now nobody is looking down their noses at somebody... I think that is what one or two had problems with initially. Like Harry and Tel, and I think that stopped them coming.' (Josh, Marching On, Interview)

The finding demonstrates the importance of a male-only environment for providing a familiar and relaxing environment where older men with dementia can express themselves and connect on a deeper, emotional level. However, it also highlights the challenges that can be encountered when managing the multiple and diverse interests that may become apparent within this environment.

\section{An empowering approach}

The approach sought to empower the men by creating a platform that promoted mutual learning and respect between the researcher and the men throughout the development of the TI. This involved reducing the power of the 'expert' researcher to enable him to move from the position of 'outsider' researcher to 'insider' of the group by joining in with group discussions and activities. The data suggested that this approach was successful as researcher's reflective notes highlighted numerous instances where overtime he became accepted by the men and they became more confident interacting with him. For instance the men in all groups began to invite him to participate in the activities and make fun of his performances. Doug (Done Roaming) began to refer to him as 
'mate' towards the end of the TI and Terry (Done Roaming) and Colin (Marching On) encouraged him to use their nicknames rather than their formal name. During feedback at one TI session, David noted that he had become a 'friend of the circle' (David, Old Boys, RFN session 7) and on another occasion, Gordon (Marching On), who was initially reserved within the group, beckoned him aside at the end of a session to a quiet corner where his wife (who had come to pick him up) couldn't hear and began to open up about an intimate occasion he had with a lady on holiday (Gordon, Marching On, RFN session 6). As Doug suggested during the final feedback session:

'Your success is in the fact that really none of us are aware of you as being in charge or a tutor, which is so important. If you think you've got a governor then you'll be more wary. But you've been part of it.' (Doug, Done Roaming, Focus Group)

In addition to reducing the power of the researcher, the approach further successfully empowered the men by positioning them as 'experts' in the development of the $\mathrm{TI}$ and encouraging them to name their group and take ownership of it. Although the men were initially reluctant to inform the $\mathrm{TI}$, overtime they became more willing, even if it might have offended the researcher. For instance, during one feedback session, the Old Boys stated the balance board games (task 14) that included skiing and tight rope walking were too difficult, not a great deal of fun and possibly better suited for a younger audience. The data collected during the final focus groups and interviews demonstrated that this approach was welcomed by the men and something that 'people I don't think are used to, especially that sort of age group and those with dementia' (Graham, Old Boys, Volunteer, Interview).

'Yeah what I like about this (the TI) and what I have always liked every day I have come to this is the fact that we move into a mould for that day which is 'what do you think boys?' and it is coming from you. 'Should we try this?' You're the leader in other words without being bossy.' (Phil, Done Roaming, Focus group) 
Some care partners also highlighted during feedback that this approach was an important mechanism for the success of the $\mathrm{TI}$.

'He thoroughly enjoyed it and every time you praised him or asked his opinion, he came away glowing! Really pleased he'd done so well with it. And he was always in a good mood afterwards and felt he had helped you with the club. He had big plans for it! (Maureen, Marching On, Care partner, interview)

'And I think your personality is important, if you'd been bossy, it wouldn't have worked at all, because men don't take to being told what to do or bossed around, but the way you handled it was brilliant!' (Jean, Done Roaming, Interview)

Furthermore, the men and their care partners suggested that providing a 'dementia-free zone' and removing the dementia focus from the TI was appealing to the men and was beneficial for their wellbeing and willingness to contribute.

'I suppose because you know you've got a problem. But everything is alright yeah. It helps that the club does not focus on the problem.' (Bill, Old Boys, Interview)

'Absolutely you don't focus on dementia and that is good. The atmosphere in the other one (group for people with dementia) is quite harrowing... is almost serious, serious medical and so very quickly you get grr (make angry noise).' (Doug, Done Roaming, Focus group)

'I mean he enjoys it...I shouldn't say this, he prefers yours because he feels better about going there, because he doesn't associate it as being part of the Dementia Club that kind of Club.' (Grace, CP, Marching On, Interview)

The findings demonstrate the importance of empowering older men with dementia when seeking to engage them, by positioning them as collaborators in the research, reducing the power of the researcher and removing any focus on dementia. 


\section{Discussion}

The TI was welcomed by the majority of men and offered them an opportunity to engage in an activity that was not currently provided within their rural environments. It achieved its success through three 'active mechanisms' (Dugmore, Orrell and Spector, 2015) that worked in tandem to appeal to them and provide them an opportunity to express and reaffirm their masculinities. These were; the enabling technological activity; the conceptually safe male-only environment; and the empowering approach.

The following discussion examines these findings through a masculinity lens to provide a theoretical understanding of how to engage community-dwelling older men with dementia in a technological initiative. It also offers recommendations for policy, practice and research concerned with implementing ecopsychosocial initiatives more broadly that seek to engage with, and raise awareness of, this hard-to-reach population as well as enhance their inclusion and well-being.

\section{- Provide opportunities to re-connect with activities associated with younger masculinities}

The TI provided a wide range of applications and games that could be tailored towards the men's interests and capabilities. This ensured they were 'meaningful' (Roland and Chappell, 2015) and appealing to the men, by enabling them to re-connect with activities that were reminiscent of their younger masculinities and sense of 'self'. This is consistent with research that suggests older men seek to maintain their engagement in activities they have undertaken throughout their lives (Genoe and Singleton, 2006; Milligan et al, 2015; Phinney, Dahlke and Purves, 2013; Wiersma and Chesser, 2011). Previously, technological initiatives have tended to offer only one device in isolation (along with a limited set of games or applications chosen in advance by the researcher), such as the Nintendo Wii (Leahey, A., \& Singleton, 2011) or iPads (Leng et al, 2014; Upton et al, 2011) and so this may limit their appeal to older men who have interests that cannot be catered for by this technology or who may struggle with some of the actions required to engage with it. Consequently, researchers and practitioners may find a more beneficial approach when delivering technological initiatives is to 
offer a wide range of devices and games/applications that are chosen by the men; thereby enabling them to be tailored towards their younger masculine leisure interests as well as their capabilities. This is also advisable for researchers and practitioners seeking to attract older men with dementia through other ecopsychosocial community initiatives. Currently, these initiatives, such as 'Men in Sheds' or football clubs (Carone, Tischler and Dening, 2016; Solari and Solomons, 2012; Tolson and Schofield, 2012), may be limited in scope and unappealing to men who, during their younger years, had limited knowledge of, or interest in, 'sheds' or football. Again, to ensure inclusivity, it is important that researchers and practitioners consider initiatives that provide a wide range of activities; thereby enabling them to be tailored to the multiple interests and masculinities of older men with dementia. A TI may be one such initiative that can achieve this and therefore warrants further exploration.

It is noteworthy that on occasions when the activities were tailored towards the men's previous leisure interests, this could evoke a sense of pressure to perform. When the men were unable to succeed, it detrimentally impacted on their well-being by emphasising their shortcomings when compared to the traditional masculinities they once aligned with. Fortunately in these rare instances, the men were able to situate the blame on the gaming technology and so diffuse any potential threat to their masculinities. However, this raises important implications for the broad brush assertion that person-centred activities are always the most appropriate for people with dementia (Kolanowski et al, 2011), and highlights the need for further research and guidance to support practitioners managing technological initiatives where these potentially difficult situations with older men with dementia can occur. This guidance may be particularly pertinent for practitioners running other ecopsychosocial initiatives, where the 'blame' for failure cannot be so easily situated on external devices, such as the technology. These instances are likely to be internalised by older men with dementia and so detrimentally impact on their perceived masculinities and sense of 'self' and well-being. 


\section{- Provide non-threatening opportunities to perform and express masculinities}

The TI provided welcomed opportunities for the men to both physically and verbally perform and express their masculinities in a non-threatening, or 'conceptually safe' (Phinney et al, 2016; Wiersma et al, 2016) environment, and through this garner respect from others present.

Through the activities, the men were enabled to display and perform physical attributes associated with their masculinities such as strength, success, capability and competitiveness, but in a relaxed context due to the jovial concepts of the games and applications. This is similar to other initiatives that seek to engage older men by providing relaxed activities (Milligan et al, 2015). Particularly interesting was the men's willingness to undertake competitive practices. This was most pronounced in the Done Roaming group where men were competing for the respect of their care partners (who unlike the other groups had stayed to watch the activities) and using them to increase their ranking and sense of masculinity compared to the other men present, as posited by Genoe and Singleton (2006). Whilst it has been highlighted that older men still engage in competitive practices (Thompson and Langendorefer, 2016) this is rarely encouraged in technological initiatives or more widely in ecopsychosocial initiatives targeted at this population, such as 'Men in Sheds,' due to an assumption that it is not wanted or required (Milligan et al, 2015). These findings suggest a need for both technological and other ecopsychosocial initiatives to provide an element of friendly competition as this may appeal to the traditional masculinities of older men with dementia.

Furthermore, they also add to the debate on the appropriateness of care partners within community initiatives for people with dementia (Wiersma et al, 2016) highlighting that within male-only initiatives, having them within eyeshot but out of earshot, may help to create a social context that encourages older men to perform these important facets of masculinity; resulting in an enhanced sense of achievement. Further research is required to explore this within the context of technological initiatives as well as broader ecopsychosocial initiatives, and to elicit ways for 
practitioners to manage these dynamics appropriately to ensure care partners do not restrict the voices and autonomy of older men with dementia.

The TI also enabled the men to verbally express their masculinities by engaging in conversation whilst undertaking activities that encouraged and supported them to provide a narrative account of their life and achievements; thus offering them a secondary means to garner respect from others. This is consistent with wider research on ecopsychosocial initiatives, where Milligan et al (2015) posits that this form of 'shoulder-to-shoulder' communication (working while talking) is favoured by older men and enhances the appeal of the 'Men in Sheds' initiative. Through similar mechanisms, this study suggests that technological initiatives using 'off-the-shelf' digital gaming technological devices (and particularly the iPad) can also provide an appealing medium for promoting communication between older men with dementia. Furthermore, these devices (particularly the iPad) may offer a more beneficial means of 'shoulder-to-shoulder' communication for older men with dementia than typical 'shed' activities, as consistent with other research (Cutler, Hicks and Innes, 2016; Dove and Astell, 2017; Joddrell and Astell, 2016; Upton et al, 2011), they are able to prompt or 'scaffold' conversations through various media and so ameliorate memory difficulties that this population may face. This enables people to talk more competently and confidently about their lives and so provides greater opportunities for them to discuss their achievements and garner respect. Further research is required to provide guidance for practitioners on using this technology, as part of a community technological initiative, in a way that can stimulate and support conversations with older men with dementia.

The male-only environment and the 'dementia-free zone' approach were important contributing factors for enabling the men to freely perform, express and reaffirm their masculinities. The consideration of these environmental influencers is novel for a technological initiative but the findings are consistent with otherecopsychosocial initiatives that engage older men (Milligan et al, 2015; Wilson and Cordier, 2013; Wilson et al, 2015) as well as those with dementia (Carone, Tischler 
and Dening, 2016). Working in tandem, these factors were able to create a conceptually safe environment that is advocated when engaging people with dementia (Dupuis et al, 2012, 2016b; Phinney et al, 2016; Wiersma et al, 2016). The male-only environment, which was novel for the men within all three rural locations, appealed to them as it enabled them to re-connect with a familiar environment that was associated with their younger masculinities as well as limited the perceived threats they experienced to these masculinities. This latter aspect is particularly important as other research (Milligan et al, 2015) has demonstrated how older men without dementia can perform actions associated with traditional hegemonic masculinities to exclude or 'other' (McParland, Kelly and Innes, 2017) those living with the condition. Therefore, creating an environment where all the men acknowledged the difficulties they faced in sustaining their masculinities, enhanced the inclusivity of the initiative. Furthermore, adopting an approach that did not encourage the men to openly discuss their dementia and the emotional challenges they may encounter, appealed to them by ensuring they could maintain an outwardly stoic resolve and not have to openly express characteristics that might be viewed as feminine; thereby threatening their sense of masculinity. Through this appealing, 'unspoken' environment, the men were able to develop a sense of community and connect on an emotional level, and this provided them support and confidence. Developing this sense of 'community' has been posited as important and beneficial when engaging people with dementia in community initiatives (Dupuis et al, 2016b; Keyes et al, 2016; Phinney et al, 2016; Wiersma et al, 2016). Researchers and practitioners wishing to run technological initiatives as well as other ecopsychosocial activities would be advised to implement 'dementia-free' spaces that only encourage older men living with dementia to participate, if they wish to successfully engage with, and create a sense of community among, this population.

\section{- Provide opportunities for older men with dementia to retain authority}

The men welcomed the opportunity to contribute as collaborators in the $\mathrm{TI}$, and enabling them a sense of authority, autonomy and agency throughout the evolution of the initiative was integral to 
its success. This is consistent with research that promotes, and highlights the empowering influence of, PAR approaches (Wiersma et al, 2016) or authentic partnerships with people with dementia (Dupuis et al, 2012, 2016a). To date, whilst these approaches are gold standard practice when developing dementia-specific technology (Kenigsberg et al, 2017; Lorenz et al, 2017; Meiland et al, 2017; Span et al, 2013) the lessons are yet to be widely adopted when developing and running both technological and wider ecopsychosocial community initiatives as a leisure activity for people with dementia. This is an important oversight to address when engaging Western older men with dementia, who may retain traditional masculine values of autonomy, agency and independence (Tannenbaum and Frank, 2011) and may feel these are threatened if working with practitioners in an unequal power relationship; potentially resulting in them suppressing thoughts and feelings during interactions and disengaging with research as a way to preserve their sense of masculinity (Genoe and Singleton, 2006). Therefore policy, research and practice would be advised to promote and adopt PAR approaches as a means to engage older men with dementia in community initiatives, including technological activities.

\section{- Provide opportunities to challenge the social construction of an 'old man'}

Through engaging with 'off-the-shelf' technology, which is ubiquitous within society, the men felt a reconnection with modern culture that they would have likely been at the forefront of as white, British men, during their younger years. For some, this was a liberating experience and enhanced the appeal of the $\mathrm{TI}$ as well as their own confidence and well-being. Furthermore, through engaging with the technology, the men challenged the negative social constructions associated with an 'old man,' which in conjunction with the physical bodily changes of ageing, can detrimentally impact on their willingness to participate in activities (Wiersma and Chesser, 2011). This highlights the benefits of using 'off-the-shelf' gaming technology when delivering technological initiatives rather than the specialised, yet potentially stigmatised dementia-specific technology. Furthermore, it is unlikely these beneficial outcomes would have been achieved through other traditional ecopsychosocial 
initiatives that use concepts such as 'the shed,' as within contemporary society these are typically associated with older men and so do not offer a space to 'resist' (Genoe, 2010) these social constructions. Therefore policy, practice and research must be more open to exploring both technological and other ecopsychosocial activities that are associated with a modern culture when engaging older men with dementia. These will provide opportunities for them to re-connect with contemporary society, and so feel less adrift from their previous masculine status, as well as challenge the typical social constructions of an 'old man' that can detrimentally impact on their sense of masculinity and their willingness to engage in community initiatives.

\section{- Managing the multiple masculinities}

As posited by other research, older men can prescribe to, and perform multiple masculinities; some of which can be akin to traditional hegemonic masculine values and others not (Twigg, 2018). Unsurprisingly therefore, creating an environment that did not seek to temper or place restrictions on the expression of these masculinities, sometimes encouraged sexist, racist and homophobic conversations as well as highlighted where the perceived social positioning, social class, interests and masculinities of the men were juxtaposed to one another; thereby leading to tensions within the groups that needed to be managed. Interestingly, this was not as evident in the Old Boys group, perhaps due to the 'bypassed' nature of the rural location that, as Keating et al (2013) posits can result in close camaraderie between residents and a willingness to endure. However, it was pronounced in the other two groups and particularly in the bucolic rural environment of the Marching On group where men from working class backgrounds were situated alongside wealthier men that resided in the expensive hamlets surrounding the rural location. Whilst in the case of Doug (Done Roaming) these clashes could be managed, primarily as they were due to his concerns of being labelled with dementia and the threats this posed for his masculinity, by emphasising the dementia-free zone and encouraging him to engage in activities and discussions with the men that centred on their lives and common interests, rather than their label of dementia. Unfortunately 
within the Marching On group these multiple masculinities were too difficult to overcome due to their conflicting natures, with Dave and Tel favouring performative masculinities that demonstrated athleticism and strength and Chris and Harry keen to highlight their intellectual abilities and discuss activities that emphasised their upper class status. As a facilitator of both technological and other ecopsychosocial initiatives it is important to recognise and appreciate the heterogeneity of people's lived experiences over and above their label of dementia (Hulko, 2009) and so acknowledge that attempts to develop solidarity between some older men with dementia may be futile. This could be particularly pertinent in bucolic rural communities as wealthier men seek these idyllic rural locations to retire to; bringing with them potentially differing and clashing masculinities than those men who have resided there throughout their lives. In these instances it may be beneficial running separate groups for older men that have similar interests thereby ensuring they can experience a sense of connection and social inclusion.

Furthermore, managing these multiple masculinities within the rural groups required the facilitator (lead author) to be flexible with his approach and emphasise different facets of his masculinity at various time, so as to develop rapport with the different men. For instance, on occasions this required drawing on more typical hegemonic masculine characteristics such as making rude jokes when engaging in 'male banter' and joining in with the competitive practices when interacting with men who appreciated these forms of masculinity, or conversely, highlighting intellectual abilities and calmness with men who valued and responded better to these attributes. This highlights the need to provide guidance to practitioners on engaging and managing the multiple and diverse masculinities, as well as the potentially difficult situations and conversations that may arise when creating a socially inclusive platform to enable older men with dementia to express and reaffirm their masculinities. This may be particularly pertinent if older men are present who would have typically occupied lower masculine status when compared to a Western hegemonic ideal, such as men who identify as gay, bisexual or transgender or who are from culturally diverse backgrounds. 


\section{Limitations of the study and suggestions for future research}

The ethnic profile of the older men with dementia was White British. Caution must therefore be taken when attempting to generalise these findings to community-dwelling older men with dementia from other ethnic backgrounds, as these cultures can also adversely impact on men's abilities to engage with health services (Regan, 2016). Future research would be advised to examine the factors for engaging community-dwelling older men from diverse cultural backgrounds, and so provide theoretical insight into these active mechanisms. Furthermore, the research was conducted within rural locations with male participants who had resided there for extended periods of time and had limited experience of using 'off-the-shelf' gaming technology. Again therefore, caution must be taken when generalising these findings to community initiatives within urban areas due to: the differing geosociocultural environments (Blackstock et al, 2006); the tendency for rural-dwelling men to align more closely with hegemonic masculine ideals when compared to urban dwelling men (Hammer, Vogel and Heimerdinger-Edwards, 2013; Levant and Habben, 2003) and; the rural/urban technological divide, which means older urban men with dementia may have more prior experience with these devices and so feel more comfortable engaging with them. This latter point is particularly pertinent for future research and practice to engage with, given that overtime urban and rural masculinities will begin to shift and the new cohorts of older men are likely to be more accepting and accustomed to technology and gaming and so expect it to be provided as part of their activities. Finally, the research used a self-selecting sample and so possibly the men had a pre-existing interest in the technology or in socialising within their rural area. As such, further mechanisms may be at play that cannot be accounted for in this research and may prevent older men with dementia from engaging with technological initiatives as well as wider community ecopsychosocial initiatives. Future studies would benefit from exploring the perceptions of older men with dementia who have never engaged with community initiatives to elicit further insights into the potential mechanisms for appealing to this hard to reach population. 


\section{Conclusion}

To the best of the authors' knowledge, this is the first paper to draw on a masculinity lens to provide a theoretical understanding of the active mechanisms for engaging rural community-dwelling older men with dementia in a technological initiative. Although the research used off-the-shelf gaming technology, the paper has outlined how the findings can be applied more widely to provide important and urgently required recommendations for practitioners seeking to establish an appealing community ecopsychosocial initiative for older men with dementia. In particular it highlights the need to acknowledge that older men with dementia retain their gendered identity and, consequently, community initiatives that wish to engage them, should provide a gendered space that enables the men to maximise their masculine capital. This can be achieved, in part, through the activities that are provided, the environment that is created and the delivery approach that is adopted.

\section{References}

Alzheimer's Disease International (2015) The Global Impact of Dementia: An analysis of prevalence, incidence, cost and trends. London: ADI

Astell, A. (2013). Technology and Fun for a Happy Old Age In A, Sixsmith, \& G, Gutman, G (Eds) Technologies for Active Aging (pp. 169-187). New York: Springer.

Australian Government (2010) National Male Health Policy. Building on the strengths of Australian males. Department of Health and Ageing: Commonwealth of Australia.

Aguirre, E., Spector, A., and Orrell, M. (2014). Guidelines for adapting cognitive stimulation therapy to other cultures. Clinical interventions in aging, 9, 1003.

Baker, S., Warburton, J., Hodgkin, S., and Pascal, J. (2017). The supportive network: rural disadvantaged older people and ICT. Ageing \& Society, 37, 1291-1309.

Baker, P. (2015). A review of the National Men's Health Policy and Action Plan 2008-2013. Health Service Executive: Dublin. 
Baker, P., Dworkin, S. L., Tong, S., Banks, I., Shand, T., and Yamey, G. (2014). The men? s health gap: men must be included in the global health equity agenda. Bulletin of the World Health Organization, 92, 618-620.

Bartlett, R., Gjernes, T., Lotherington, A. T., and Obstefelder, A. (2018). Gender, citizenship and dementia care: a scoping review of studies to inform policy and future research. Health \& social care in the community, $26,14-26$.

Blackstock, K., Innes, A., Cox, S., Smith, A., and Mason, A. (2006). Living with dementia in rural and remote Scotland: diverse experiences of people with dementia and their carers. Journal of rural studies, 22, 161-176.

Bowes, A., Dawson, A., and McCabe, L. (2018). RemoDem: Delivering support for people with dementia in remote areas. Dementia, 17, 297-314.

Braun, V., and Clarke, V. (2006). Using thematic analysis in psychology. Qualitative research in psychology, 3, 77-101.

Bryce, H. (2013). Navigating multiple roles as a researcher in a Photovoice project. Groupwork, 22, $33-48$.

Carone, L., Tischler, V., and Dening, T. (2016). Football and dementia: A qualitative investigation of a community based sports group for men with early onset dementia. Dementia, 15, 13581376.

Chevalier, J. M., and Buckles, D. (2013). Participatory action research: Theory and methods for engaged inquiry: New York: Routledge.

Cohen-Mansfield, J., Marx, M. S., Dakheel-Ali, M., Regier, N. G., and Thein, K. (2010). Can persons with dementia be engaged with stimuli? The American Journal of Geriatric Psychiatry, 18, 351-362.

Connell, R. W.,(2005). Masculinities ( $2^{\text {nd }}$ Edition). Polity Press: Cambridge.

Connell, R. W., and Messerschmidt, J. W. (2005). Hegemonic masculinity rethinking the concept. Gender and Society, 19, 829-859. 
Connell, R,. and Pearse, R. (2015) Gender: In World Perspective (3rd edn). Polity: Cambridge.

Cordier, R., and Wilson, N. J. (2014). Community-based Men's Sheds: promoting male health, wellbeing and social inclusion in an international context. Health promotion international, 29, 483-493.

Coston, B., and Kimmel, M. (2013). Aging men, masculinity and Alzheimer's: Caretaking and caregiving in the new millennium. In Kampf, A., Marshall, B, L., and Petersen, A. Ageing Men, Masculinities and Modern Medicine (191-200). London: Taylor and Francis.

Courtenay, W. H. (2000). Constructions of masculinity and their influence on men's well-being: a theory of gender and health. Social science \& medicine, 50, 1385-1401.

Cutler, C. (2018). Quality of life and digital gaming technology: the benefits of a technology based intervention for community dwelling people with dementia. A PhD Thesis. Bournemouth: Bournemouth University.

Cutler, C., Hicks, B., and Innes, A. (2016). Does digital gaming enable healthy aging for communitydwelling people with dementia? Games and Culture, 11, 104-129.

Department for Environment, Food and Rural Affairs (2015). Defining rural areas. London: DEFRA

Dewing, J. (2008). Process consent and research with older persons living with dementia. Research Ethics Review, 4, 59-64.

Dove, E., and Astell, A. J. (2017). The use of motion-based technology for people living with dementia or mild cognitive impairment: a literature review. Journal of Medical Internet Research, 19.

Dugmore, O., Orrell, M., and Spector, A. (2015). Qualitative studies of psychosocial interventions for dementia: a systematic review. Aging \& Mental Health, 19, 955-967.

Dupuis, S., McAiney, C. A., Fortune, D., Ploeg, J., and Witt, L. D. (2016a). Theoretical foundations guiding culture change: The work of the Partnerships in Dementia Care Alliance. Dementia, 15, 85-105. 
Dupuis, S. L., Kontos, P., Mitchell, G., Jonas-Simpson, C., and Gray, J. (2016b). Re-claiming citizenship through the arts. Dementia, 15, 358-380.

Dupuis, S. L., Gillies, J., Carson, J., Whyte, C., Genoe, R., Loiselle, L., and Sadler, L. (2012). Moving beyond patient and client approaches: Mobilizing 'authentic partnerships' in dementia care, support and services. Dementia, 11, 427-452.

Fenney, A., and Lee, T. D. (2010). Exploring Spared Capacity in Persons With Dementia: What WiiTM Can Learn. Activities, Adaptation \& Aging, 34, 303-313.

Flick, U. (2014). An introduction to qualitative research. London: Sage.

Genoe, M. R. (2010). Leisure as resistance within the context of dementia. Leisure Studies, 29, 303320.

Genoe, M. R., and Singleton, J. F. (2006). Older men's leisure experiences across their lifespan. Topics in Geriatric Rehabilitation, 22, 348-356.

Hammer, J. H., Vogel, D. L., and Heimerdinger-Edwards, S. R. (2013). Men's help seeking: Examination of differences across community size, education, and income. Psychology of Men \& Masculinity, 14, 65.

Hicks, B. (2016) Exploring the use of a commercial digital gaming Technological Initiative to enable social inclusion for community-dwelling older men with dementia in rural England. A PhD Thesis. Bournemouth: Bournemouth University.

Hicks, B., and Miller, L. (2012). Research to inform the development of a guide for online activities for people with dementia: London: Social Care Institute for Excellence.

Hulko, W. (2009). From 'not a big deal' to 'hellish': Experiences of older people with dementia. Journal of Aging Studies, 23, 131-144.

Hurd Clarke, L. and Bennett, E. (2013). 'You learn to live with all the things that are wrong with you': gender and the experience of multiple chronic conditions in later life. Ageing \& Society, 33, 342-360. 
Hurd Clarke, L. and Lefkowich, M. (2018). 'I don't really have any issue with masculinity': Older Canadian men's perceptions and experiences of embodied masculinity. Journal of aging studies, $45,18-24$.

Joddrell, P., and Astell, A. J. (2016). Studies involving people with dementia and touchscreen technology: a literature review. JMIR Rehabilitation and Assistive Technologies, 3.

Kahlbaugh, P. E., Sperandio, A. J., Carlson, A. L., and Hauselt, J. (2011). Effects of playing wii on wellbeing in the elderly: physical activity, loneliness, and mood. Activities, Adaptation \& Aging, 35, 331-344.

Kaufman, M.(1994). Men, feminism, and men's contradictory experiences of power. In H. Brod \& M. Kaufman (eds). Theorizing masculinities. Thousand Oaks: Sage.

Keating, N., Eales, J., and Phillips, J. E. (2013). Age-friendly rural communities: Conceptualizing 'bestfit'. Canadian Journal on Aging, 32, 319-332.

Kenigsberg, P.-A., Aquino, J.-P., Berard, A., Gzil, F., Andrieu, S., Banerjee, S., Bremond, F., Buee, L., Cohen-Mansfield, J., Mangialasche, F., Platel, H., Salmon, E., \& Robert, P (2016). Dementia beyond 2025: Knowledge and uncertainties. Dementia, 15, 6-21.

Kenigsberg, P. A., Aquino, J. P., Bérard, A., Brémond, F., Charras, K., Dening, T et al.,. (2017). Assistive technologies to address capabilities of people with dementia: from research to practice. Dementia, doi.org/10.1177/1471301217714093

Keyes, S.E., Clarke, C.L., Wilkinson, H., Alexjuk, E.J., Wilcockson, J., Robinson, L., Reynolds, J., McClelland, S., Corner, L. and Cattan, M., (2016). "We're all thrown in the same boat...": A qualitative analysis of peer support in dementia care. Dementia, 15, pp.560-577.

Kimmel, M.S. (1996). Manhood in America. New York, NY: Free Press

Kolanowski, A., Litaker, M., Buettner, L., Moeller, J., and Costa, J. P. T. (2011). A Randomized Clinical Trial of Theory-Based Activities for the Behavioral Symptoms of Dementia in Nursing Home Residents. Journal of the American Geriatrics Society, 59, 1032-1041 
Leahey, A., and Singleton, J. F. (2011). Utilizing Therapeutic Recreation to Empower Persons with Alzheimer's in a Day Center. Therapeutic Recreation Journal, 45, 135-146.

Levant, R.F., and Habben, C. (2003). The new psychology of men: Application to rural men. In B.Stamm, (Eds) Rural behavioural health care: An interdisciplinary guide (pp171-180). Washington, DC: American Psychological Association.

Lorenz, K., Freddolino, P. P., Comas-Herrera, A., Knapp, M., and Damant, J. (2017). Technology-based tools and services for people with dementia and carers: Mapping technology onto the dementia care pathway. Dementia, 1471301217691617.

McParland, P., Kelly, F., and Innes, A. (2017). Dichotomising dementia: is there another way? Sociology of health \& illness, 39, 258-269.

Meiland, F., Innes, A., Mountain, G., Robinson, L., van der Roest, H., García-Casal, J.A., Gove, D., Thyrian, J.R., Evans, S., Dröes, R.M. and Kelly, F. (2017). Technologies to support communitydwelling persons with dementia: a position paper on issues regarding development, usability, effectiveness and cost-effectiveness, deployment, and ethics. JMIR rehabilitation and assistive technologies, 4.

Milligan, C., Payne, S., Bingley, A., and Cockshott, Z. (2015). Place and wellbeing: shedding light on activity interventions for older men. Ageing \& Society, 35, 124-149.

Nyman, S. R., and Szymczynska, P. (2016). Meaningful activities for improving the wellbeing of people with dementia: beyond mere pleasure to meeting fundamental psychological needs. Perspectives in public health, 136, 99-107.

Orrell, M. (2012). The new generation of psychosocial interventions for dementia care. The British Journal of Psychiatry, 201, 342-343.

Oyebode, J. R., and Parveen, S. (2016). Psychosocial interventions for people with dementia: An overview and commentary on recent developments. Dementia, DOI:10.1177/1471301216656096 
Phinney, A., Dahlke, S., and Purves, B. (2013). Shifting Patterns of Everyday Activity in Early Dementia Experiences of Men and Their Families. Journal of family nursing, 19, 348-374.

Phinney, A., Kelson, E., Baumbusch, J., O'Connor, D., and Purves, B. (2016). Walking in the neighbourhood: Performing social citizenship in dementia. Dementia, 15, 381-394.

Ravneberg, B. (2012). Usability and abandonment of assistive technology. Journal of Assistive Technologies, 6, 259-269.

Reason, P., and Bradbury, H. (2008) The Sage Handbook of Action research: Participative Inquiry and Practice (2 $2^{\text {nd }}$ Edition). London: Sage.

Regan, J. L. (2016). Ethnic minority, young onset, rare dementia type, depression: A case study of a Muslim male accessing UK dementia health and social care services. Dementia, 15, 702-720.

Robson, C. (2011). Real world research: a resource for users of social research methods in applied settings: Wiley Chichester.

Roland, K. P., and Chappell, N. L. (2015). Meaningful activity for persons with dementia: Family caregiver perspectives. American Journal of Alzheimer's Disease and other Dementias, 30 , 559-568.

Sandberg, L. J. (2018). Dementia and the gender trouble?: Theorising dementia, gendered subjectivity and embodiment. Journal of aging studies, 45, 25-31.

Slevin, K. F., and Linneman, T. J. (2010). Old gay men's bodies and masculinities. Men and Masculinities, 12, 483-507.

Sloan, C., Conner, M., and Gough, B. (2015). How does masculinity impact on health? A quantitative study of masculinity and health behavior in a sample of UK men and women. Psychology of Men \& Masculinity, 16, 206.

Schneider, B. (2012). Participatory action research, mental health service user research, and the hearing (our) voices projects. International Journal of Qualitative Methods, 11, 152-165.

Solari, C. A., and Solomons, L. (2012). The World Cup effect: Using football to engage men with dementia. Dementia, 11, 699-702. 
Span, M., Hettinga, M., Vernooij-Dassen, M., Eefsting, J., and Smits, C. (2013). Involving people with dementia in the development of supportive IT applications: A systematic review. Ageing Research Reviews, 12, 535-551.

Spindler, E. (2015) 'Beyond the Prostate: Brazil's National Healthcare Policy for Men', EMERGE Case Study 1, Promundo-US, Sonke Gender Justice and the Institute of Development Studies, Brighton:IDS

Szymczynska, P., Innes, A., Mason, A., and Stark, C. (2011). A review of diagnostic process and postdiagnostic support for people with dementia in rural areas. Journal of primary care \& community health, 2, 262-276.

Tannenbaum, C., and Frank, B. (2011). Masculinity and health in late life men. American Journal Of Men's Health, 5, 243-254.

Thompson Jr, E. H., and Bennett, K. M. (2015). Measurement of masculinity ideologies: A (critical) review. Psychology of Men \& Masculinity, 16, 115.

Thompson Jr, E. H., and Langendorefer, K. B. (2016). Older Men's Blueprint for "Being a Man". Men and Masculinities, 19, 119-147.

Tolson, D., and Schofield, I. (2012). Football reminiscence for men with dementia: lessons from a realistic evaluation. Nursing inquiry, 19, 63-70.

Townsend, L., Sathiaseelan, A., Fairhurst, G., and Wallace, C. (2013). Enhanced broadband access as a solution to the social and economic problems of the rural digital divide. Local Economy, 28, 580-595.

Twigg, J. (2018) Dress, Gender and the Embodiment of Age: Men and Masculinities. Ageing \& Society. doi:https://doi.org/10.1017/S0144686X18000892

Upton, D., Upton, P., Jones, T., Jutlla, K., Brooker, D., and Grove, H. (2011). Evaluation of the impact of touch screen technology on people with dementia and their carers within care home settings. UK: University of Worcester. 
Waling, A., and Fildes, D. (2017). 'Don't fix what ain't broke': evaluating the effectiveness of a Men's Shed in inner-regional Australia. Health \& social care in the community, 25, 758-768.

Wentzell, E. A. (2013). Maturing masculinities: Aging, chronic illness, and viagra in Mexico. Duke University Press.

White, A. (2011). The state of men's health in Europe: how do we compare in the UK? Trends in Urology \& Men's Health, 2, 12-16.

White, A., de Sousa, B., de Visser, R., Hogston, R., Madsen, S.A., Makara, P., Richardson, N., and Zatonski, W (2011). The state of men's health in Europe report: European Union.

Whitehouse, P. J. (2014). The end of Alzheimer's disease-From biochemical pharmacology to ecopsychosociology: A personal perspective. Biochemical pharmacology, 88, 677-681.

Wiersma, E., and Chesser, S. (2011). Masculinity, ageing bodies, and leisure. Annals of Leisure Research, 14, 242-259.

Wiersma, E. C., O'Connor, D. L., Loiselle, L., Hickman, K., Heibein, B., Hounam, B., and Mann, J. (2016). Creating space for citizenship: The impact of group structure on validating the voices of people with dementia. Dementia, 15, 414-433.

Wilson, N. J., and Cordier, R. (2013). A narrative review of Men's Sheds literature: reducing social isolation and promoting men's health and well-being. Health \& social care in the community, 21, 451-463.

Wilson, N. J., Cordier, R., Doma, K., Misan, G., and Vaz, S. (2015). Men's Sheds function and philosophy: towards a framework for future research and men's health promotion. Health Promotion Journal of Australia, 26, 133-141.

Yousaf, O., Grunfeld, E. A., and Hunter, M. S. (2015). A systematic review of the factors associated with delays in medical and psychological help-seeking among men. Health psychology review, 9, 264-276. 
Zeisel, J., Reisberg, B., Whitehouse, P., Woods, R., and Verheul, A. (2016). Ecopsychosocial interventions in cognitive decline and dementia: a new terminology and a new paradigm. American Journal of Alzheimer's Disease \& Other Dementias, 31, 502-507.

Table 1: Demographic overview of the three rural locations

\begin{tabular}{|c|c|c|c|}
\hline Demographic data & Location One & Location Two & Location Three \\
\hline Rural-Urban classification & $\begin{array}{l}\text { Rural town } \\
\text { and fringe }\end{array}$ & $\begin{array}{l}\text { Rural town } \\
\text { and fringe }\end{array}$ & $\begin{array}{l}\text { Rural town and } \\
\text { fringe }\end{array}$ \\
\hline Population & 4,013 & 5,496 & 7,314 \\
\hline Males & $2,254(56 \%)$ & $2,563(47 \%)$ & $3,488(48 \%)$ \\
\hline Population over 65 & $\begin{array}{l}577 \text { (14\% with } \\
7 \% \text { males) }\end{array}$ & $\begin{array}{l}1,504(27 \% \\
\text { with } 11.5 \% \\
\text { males) }\end{array}$ & $\begin{array}{l}1,613 \text { ( } 22 \% \text { with } \\
8.5 \% \text { males })\end{array}$ \\
\hline Median age & 40 & 50 & 43 \\
\hline $\begin{array}{l}\text { Population density per } \\
\text { hectare }\end{array}$ & 12 & 8.6 & 16.3 \\
\hline $\begin{array}{l}\text { Day to day activities } \\
\text { limited }\end{array}$ & $21.8 \%$ & $21.5 \%$ & $17.6 \%$ \\
\hline Health very good/good & $78.2 \%$ & $78.9 \%$ & $82.4 \%$ \\
\hline Health very bad/bad & $6.2 \%$ & $6 \%$ & $4.2 \%$ \\
\hline
\end{tabular}




\begin{tabular}{|l|l|l|l|}
\hline Provide unpaid care & $10.3 \%$ & $12.9 \%$ & $10 \%$ \\
\hline White British & $89.8 \%$ & $96.3 \%$ & $93.3 \%$ \\
\hline $\begin{array}{l}\text { Economically active (\% of } \\
\text { those aged 16-74) }\end{array}$ & $62.7 \%$ & $67.9 \%$ & $73.8 \%$ \\
\hline High skill occupation & $28 \%$ & & \\
\hline Low skill occupation & $28.2 \%$ & $32.8 \%$ & $32.9 \%$ \\
\hline
\end{tabular}

Table 2: Overview of the Technology Initiative

\begin{tabular}{|c|c|c|c|c|c|}
\hline $\begin{array}{l}\text { Name of } \\
\text { each TI } \\
\text { (named by } \\
\text { the men } \\
\text { attending) }\end{array}$ & $\begin{array}{l}\mathrm{N} \text { men } \\
\text { starting } \\
\mathrm{TI}\end{array}$ & $\begin{array}{l}\mathrm{N} \text { men } \\
\text { completing } \\
\mathrm{TI}\end{array}$ & $\begin{array}{l}\text { Length of TI } \\
\text { (weeks between } \\
\text { Aug-Oct 2014) }\end{array}$ & $\begin{array}{l}\text { Technology and application/game } \\
\text { (session of } \mathrm{TI} \text { )* }\end{array}$ & $\begin{array}{l}\text { N Care } \\
\text { Partners } \\
\text { present } \\
\text { (not } \\
\text { participati } \\
\text { ng but in } \\
\text { eyeshot) }\end{array}$ \\
\hline Old Boys & 6 & 5 & $\begin{array}{l}9 \text { (1 session per } \\
\text { week lasting } 2 \\
\text { hrs) }\end{array}$ & $\begin{array}{l}\text { iPad- Camera (1), YouTube (all sessions), } \\
\text { Game of Life (2), Google Earth }(3,7) \text {, } \\
\text { Music and board games }(4,5,8) \\
\text { Kinect- Golf }(1,3) \text {, Tennis (3), Bowling } \\
(5,7,9) \text {, Darts (7), Fishing (5) } \\
\text { Wii- create Mii (4), Boxing (4), Mario Kart } \\
\text { (7), Motion games (6), Bowling (6), } \\
\text { Beatles Rock Band (8) }\end{array}$ & 1 \\
\hline
\end{tabular}




\begin{tabular}{|c|c|c|c|c|c|}
\hline & & & & Balance Board- Balance games (8) & \\
\hline $\begin{array}{l}\text { Done } \\
\text { Roaming }\end{array}$ & 5 & 5 & $\begin{array}{l}9 \text { (1 session per } \\
\text { week lasting } 2 \\
\text { hrs) }\end{array}$ & $\begin{array}{l}\text { iPad- Camera (1), YouTube (all sessions), } \\
\text { Game of Life (2), Google Earth }(3,4) \text {, } \\
\text { Music and board games }(3,5,6,7,8) \\
\text { Kinect- Golf }(1,6) \text {, Bowling }(5,7,9) \\
\text { Wii- Mario Kart (4), Motion games (6) } \\
\text { Balance Board- Balance games (7) }\end{array}$ & 5 \\
\hline $\begin{array}{l}\text { Marching } \\
\text { On }\end{array}$ & 11 & 6 & $\begin{array}{l}9 \text { (1 session per } \\
\text { week lasting } 2 \\
\text { hrs) }\end{array}$ & $\begin{array}{l}\text { iPad- Camera (1), YouTube (all sessions), } \\
\text { Game of Life (2), Google Earth }(3,5) \text {, } \\
\text { Music and board games }(3,8) \\
\text { Kinect- Golf }(1,5,8) \text {, Tennis }(3,5) \text {, Bowling } \\
(4,6,9) \text {, Darts (6) } \\
\text { Wii- create Mii (3), Boxing (3), Mario Kart } \\
\text { (4), Motion games (6), Bowling (7) } \\
\text { Balance Board- Balance games (7) }\end{array}$ & None \\
\hline
\end{tabular}

Notes: $\mathrm{TI}=$ Technology Initiative. ${ }^{*}$ Games varied in each $\mathrm{TI}$ according to the interests and capabilities of the men as advocated by a person-centred approach (Cohen-Mansfield, 2013; Kolanowski et al, 2011)

Table 3: Demographics of participants

\begin{tabular}{|c|c|c|c|c|c|c|}
\hline Group & $\begin{array}{c}\text { Men's } \\
\text { Pseudonym }\end{array}$ & Age & Years since & Years in & Attend other & Care partner \\
(pseudonym) & diagnosis & residence & dementia groups & No & Wife (Linda) \\
\hline Old Boys & Keith & 74 & 3 & 65 & No \\
\hline
\end{tabular}




\begin{tabular}{|c|c|c|c|c|c|c|}
\hline & David & 68 & 2 & 20 & No & Wife (Anita) \\
\hline & Joe & 71 & 4 & 25 & No & Wife (Sheila) \\
\hline & Ken & 78 & 8 & 78 & No & Wife (Iris) \\
\hline & Bill & 87 & 2 & 23 & No & Wife (Barbara) \\
\hline & Bob & 75 & 10 & 75 & Yes & Wife (Caroline) \\
\hline & $\begin{array}{l}\text { Graham } \\
\text { (volunteer) }\end{array}$ & 66 & NA & 1 & $\mathrm{NA}$ & NA \\
\hline & Tom (volunteer) & 63 & NA & 22 & NA & NA \\
\hline Done & Phil & 77 & 7 & 12 & Yes & Wife (Maggie) \\
\hline Roaming & Doug & 90 & 1 & 10 & Yes & Wife (Alison) \\
\hline & Terry & 82 & 2 & 19 & Yes & Wife (Jean) \\
\hline & Norman & 83 & 3 & 83 & Yes & Wife (Joan) \\
\hline & Barry & 84 & 3 & 15 & Yes & Wife (Betty) \\
\hline & $\begin{array}{c}\text { Greg } \\
\text { (volunteer) }\end{array}$ & 79 & NA & 30 & $\mathrm{NA}$ & NA \\
\hline Marching & Jess & 86 & 5 & 52 & Yes & Lives alone \\
\hline On & Gordon & 76 & 2 & 11 & Yes & Wife (Shirley) \\
\hline & Tel & 81 & 3 & 64 & No & Lives alone \\
\hline & Dick & 90 & 7 & 28 & No & Wife (Rita) \\
\hline & Colin & 79 & 7 & 32 & Yes & Wife (Sue) \\
\hline & John & 84 & 11 & 7 & Yes & Wife (Angela) \\
\hline & Harry & 70 & 7 & 25 & Yes & Wife (Veronica) \\
\hline & Chris & 77 & 12 & 20 & Yes & $\begin{array}{c}\text { Wife } \\
\text { (Thomasina) }\end{array}$ \\
\hline & Simon & 85 & 3 & 11 & Yes & Employed live- \\
\hline
\end{tabular}




\begin{tabular}{|c|c|c|c|c|c|c|}
\hline & & & & & & in helpers \\
(Maureen, \\
\end{tabular}

*All participants were White British ethnicity

Table 4: Overview of the research methods

\begin{tabular}{|c|c|c|c|c|c|}
\hline Group & Men & Number of sessions & & esearch Meth & \\
\hline & & & $\begin{array}{c}\text { Focus } \\
\text { Group (end } \\
\text { of TI) }\end{array}$ & $\begin{array}{c}\text { Interview } \\
\text { (immediately } \\
\text { post-TI in } \\
\text { Nov/Dec } \\
\text { 2014) }\end{array}$ & $\begin{array}{c}\text { Care } \\
\text { Partner } \\
\text { telephone } \\
\text { interview } \\
\text { (post-TI) }\end{array}$ \\
\hline \multirow[t]{2}{*}{ Old Boys } & Keith & (left due to poor health) & $x$ & $x$ & $x$ \\
\hline & David & 9 & $\checkmark$ & $\checkmark$ & $x$ \\
\hline
\end{tabular}




\begin{tabular}{|c|c|c|c|c|c|}
\hline & Kenneth & 8 & $\checkmark$ & $\checkmark$ & $\checkmark$ \\
\hline & Ken & 7 & $\checkmark$ & $x$ & $x$ \\
\hline & Bill & 8 & $x$ & $\checkmark$ & $\checkmark$ \\
\hline & Bob & 9 & $\checkmark$ & $\checkmark$ & $\checkmark$ \\
\hline & $\begin{array}{c}\text { Graham } \\
\text { (volunteer) }\end{array}$ & 6 & NA & $\checkmark$ & NA \\
\hline & $\begin{array}{c}\text { Tom } \\
\text { (volunteer) }\end{array}$ & 8 & NA & $\checkmark$ & NA \\
\hline & Phil & 8 & $\checkmark$ & $\checkmark$ & $\checkmark$ \\
\hline & Doug & 7 & $\checkmark$ & $\checkmark$ & $\checkmark$ \\
\hline & Terry & 8 & $x$ & $\checkmark$ & $\checkmark$ \\
\hline Roaming & Norman & 9 & $\checkmark$ & $\checkmark$ & $\checkmark$ \\
\hline & Barry & 8 & $x$ & $\checkmark$ & $\checkmark$ \\
\hline & $\begin{array}{c}\text { Greg } \\
\text { (volunteer) }\end{array}$ & 9 & NA & $\checkmark$ & NA \\
\hline & Jess & 9 & $\checkmark$ & $\checkmark$ & NA \\
\hline Marching & Gordon & 9 & $\checkmark$ & $\checkmark$ & $\checkmark$ \\
\hline Un & Tel & $\begin{array}{c}4 \\
\text { (left due to concerns with }\end{array}$ & $x$ & $\checkmark$ & NA \\
\hline
\end{tabular}




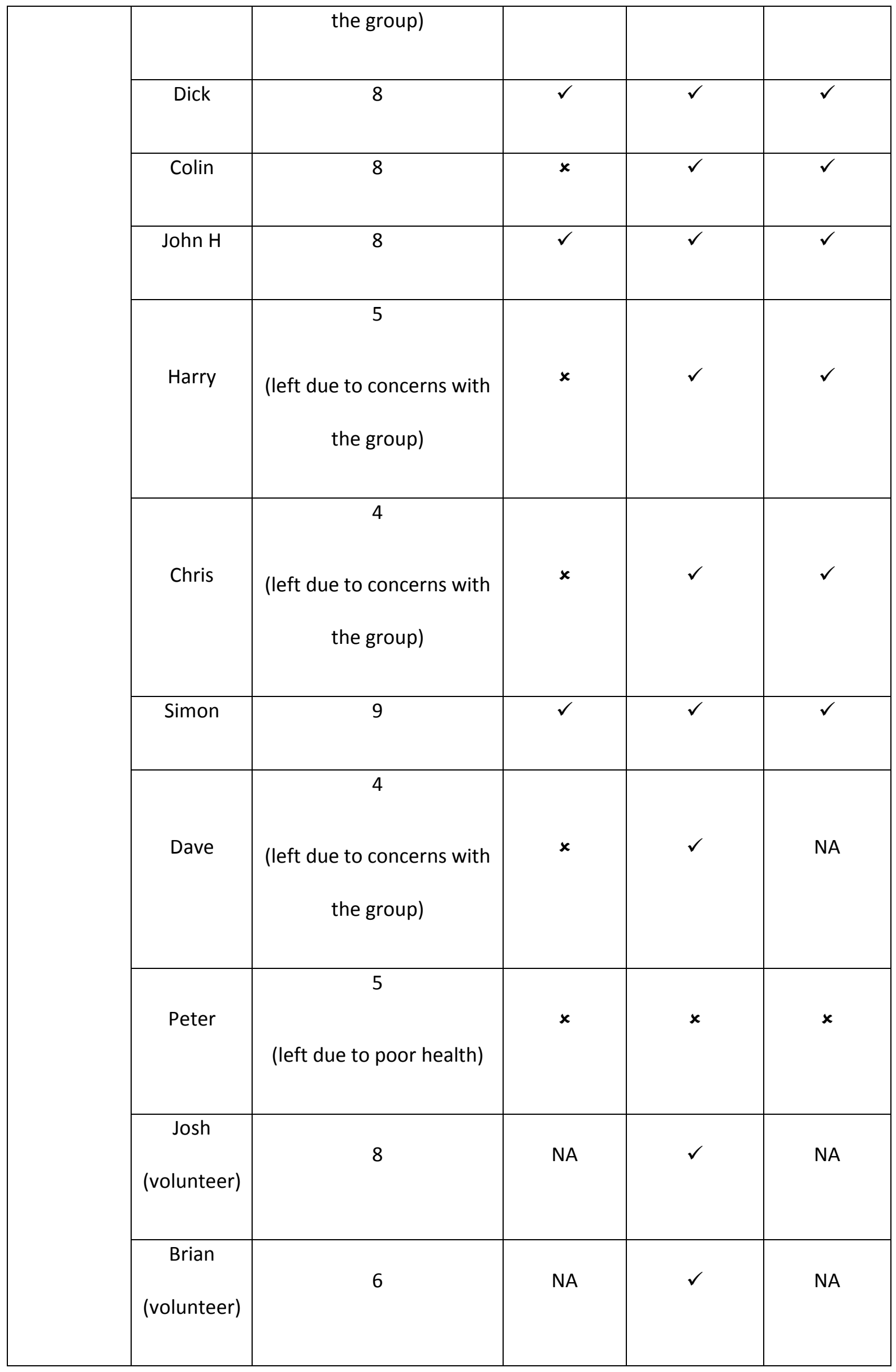


